\title{
Pediatric chest ultrasound versus conventional radiology: experimental evidence first
}

\author{
Francesco Raimondi • Luigi Cattarossi • Roberto Copetti
}

Received: 21 January 2014 / Accepted: 12 February 2014 / Published online: 12 March 2014

(C) Springer-Verlag Berlin Heidelberg 2014

Sir,

Reading the critical appraisal of chest ultrasound in children by Tomà and Owens [1], one has to fully endorse the authors' word of caution against an uncritical replacement of the standard radiograph by an ultrasound scan. Indeed, recent data from adult and pediatric emergency physicians show that each technique might prevail over the other depending on the clinical issue and that no ultrasonography superiority, per se, can be justified.

As an example, US monitors the fluid-to-air transition of the neonatal lung when, to quote Tomà and Owens, "under normal circumstances neonates improve rapidly and only one or two chest radiographs are obtained." Any neonatologist knows that those chest radiographs do not predict the abnormal but often critical circumstance of the newborn failing to adapt to the extrauterine environment. Chest US has been reported to give this important piece of information, and further trials are welcomed [2]. On the other hand, Copetti and Cattarossi [3] correctly underlined that US yields to radiology in the follow-up of neonatal respiratory distress after surfactant administration. The same authors first found the high value of US in diagnosing pediatric pneumonia [4], a finding that has been recently confirmed by a large multicenter trial in the United States [5].
Unfortunately, in the critical appraisal by Tomà and Owens [1] the objective evaluation of these experimental data and of those increasingly produced worldwide is constantly neglected in the fear of "the misuse or the abuse of paediatric chest ultrasound." Under these circumstances, we would gladly join Galileo in pronouncing "And yet, it moves."

Conflict of interest None

\section{References}

1. Tomà P, Owens C (2013) Chest ultrasound in children: critical appraisal. Pediatr Radiol 43:1427-1434

2. Raimondi F, Migliaro F, Sodano A et al (2012) Can neonatal lung ultrasound monitor fluid clearance and predict the need of respiratory support? Crit Care 16:R22

3. Copetti R, Cattarossi L, Poskurica B (2010) Surfactant administration for neonatal respiratory distress does not improve lung interstitial fluid clearance: echographic and experimental evidence. J Perinat Med 38: 557-563

4. Copetti R, Cattarossi L (2008) Ultrasound diagnosis of pneumonia in children. Radiol Med 113:190-198

5. Shah VP, Tunik MG, Tsung JW (2013) Prospective evaluation of point-of-care ultrasonography for the diagnosis of pneumonia in children and young adults. JAMA Pediatr 167:119-125

\author{
F. Raimondi $(\bowtie)$ \\ Division of Neonatology, \\ Department of Medical Translational Sciences, \\ University of Naples Federico II, via Pansini 5, 80121 Naples, Italy \\ e-mail: raimondi@unina.it \\ L. Cattarossi \\ Department of Neonatology, \\ University Hospital of Santa Maria della Misericordia, \\ Udine, Italy

\section{R. Copetti} \\ Emergency Department, Latisana General Hospital, Latisana, Italy
}

